(C2008 IEEE. Personal use of this material is permitted. However, permission to reprint/republish this material for advertising or promotional purposes or for creating new collective works for resale or redistribution to servers or lists, or to reuse any copyrighted component of this work in other works must be obtained from the IEEE 


\title{
Characterization of Suburban Areas for Land Use Planning Using Landscape Ecological Indicators Derived From Ikonos-2 Multispectral Imagery
}

\author{
Darrel R. Greenhill, Lennart T. Ripke, Adrian P. Hitchman, Graeme A. Jones, and Graeme G. Wilkinson, Member, IEEE
}

\begin{abstract}
Very high resolution satellite images are used to derive the spatial distributions of landscape ecological metrics within suburban areas. These indicators are weighted mean patch size and lacunarity computed from thresholded normalized difference vegetation index obtained from multispectral IKONOS-2 imagery. Spatial distributions of the metrics are derived for an extensive suburban area on the southwest edge of London, U.K. Weighted mean patch size and lacunarity values have also been investigated in subimages corresponding to different kinds of suburban land cover and with different box sizes. The results indicate typical ranges of the metrics in environmentally sustainable localities. The spatial distributions of the metrics provide new insight into landscape structure, which can be exploited in land use planning and in the construction of empirical spatial planning heuristics for sustainable urban development.
\end{abstract}

Index Terms-IKONOS multispectral data, landscape ecology, landscape metrics, suburban land cover, urban development.

\section{INTRODUCTION}

$\mathbf{T}$ HERE IS A significant global trend toward the increasing urbanization of the human population with a gradual displacement of work and people toward city areas and away from rural areas. This is not a new phenomenon but the pace of urbanization has been growing with the shift of employment toward high-technology or knowledge-based activities. Most cities in the world are in a state of continual growth facing regional planners with difficult choices over where to permit new housing and industrial development. The southeast of England, and in particular the London area, is a region that currently faces significant future planning challenges. The U.K. Government recently estimated that a further 200000 homes would be needed in and around London in the next ten years. The government is also committed to the goal of sustainable development, which puts significant constraints on land development policies.

So far remote sensing has not been widely used in land use planning by regional authorities. Several authors have however

Manuscript received October 18, 2002; revised March 14, 2003. This work was supported by the U.K. Science Research Investment Fund.

D. R. Greenhill and G. A. Jones are with the Digital Imaging Research Centre, School of Computing and Information Systems, Kingston University, Surrey KT1 2EE, U.K.

L. T. Ripke is with the Faculty of Mathematics and Science, Optical Technology and Image Processing, University of Applied Sciences Darmstadt, D-64295 Darmstadt, Germany.

A. P. Hitchman is with the Sustainable Technology Research Centre, Faculty of Technology, Kingston University, Surrey KT1 2EE, U.K.

G. G. Wilkinson is with the Faculty of Applied Computing Sciences, University of Lincoln, Lincoln LN6 7TS, U.K.

Digital Object Identifier 10.1109/TGRS.2003.814629 recognized the potential of remote sensing as a useful tool that can help urban planners [1] and a number of studies have examined the use of remote sensing in understanding urban landscape form and its evolution [2]-[4]. There has been growing interest in the monitoring of urban and suburban environments by remote sensing in recent years as a consequence both of the interest in improving urban environmental quality and of the increase in sensor spatial resolution. There have been a number of studies on the mapping of urban and suburban land cover using classification of multispectral remotely sensed imagery, e.g., [5]. Given the complexity of urban and suburban landscapes, innovative classification methods have been developed using kernel-based spatial reclassification [6], [7], combinations of large numbers of textural features [8], use of Gabor filters [9] and also fuzzy approaches using statistical and neural network methods [10], [11]. In some urban and suburban studies, remotely sensed imagery has been complemented by ancillary geographical data from global information systems [12], [13]. Synthetic aperture radar imagery is also now yielding important new results in urban monitoring [14].

From the perspective of sustainable land use development, the characterization of the environmental quality of urban landscapes becomes especially important. The environmental quality is controlled by many factors such as presence of vegetated areas and of derelict areas, housing density, climate quality, and extent of impervious surfaces. Attempts have been made to monitor and model these factors by use of remote sensing data, e.g., [15]-[21].

\section{SCOPE OF THIS PAPER}

Most of the previous work on the use of remote sensing for urban or suburban studies has focused on pixel-level or parcellevel land use classification. Whilst mapping of land use in this way makes an important contribution to environmental analysis, a full understanding of the suitability of areas for development must take into account aspects of the surrounding landscape and the overall regional pattern of land use. This can be achieved with remote sensing through the use of approaches derived from "landscape ecology" and in particular through the extraction of landscape metrics [22]. Several different types of landscape metrics can be derived from satellite imagery. These include lacunarity [23], Korcak patchiness exponent, and area-perimeter fractal dimension [24]. Such metrics can provide information about the spatial distributions of vegetated and built-up areas and the relationships between them. In [24], such metrics were 
applied to the analysis of deforestation patterns in the Amazon, and in [25] they were used to analyze rangelands. In this paper, landscape metrics have been derived from suburban imagery on the edge of London, in an area which is undergoing significant land use change as a result of the regional demand for new housing. The aim of this work has been to identify novel approaches for visualizing land use in terms of landscape metrics and in so doing to provide new approaches that can be of use to regional planners. Very high resolution satellite imagery has been chosen for this purpose, as it maximizes the detectability of small-scale features such as roads which separate vegetated areas. From an ecological perspective, a road is a barrier to flora and fauna and needs to be extracted and included in analysis focusing on environmental quality. In addition, the connectivity and spatial cooccurrence of small green islands such as gardens in densely built-up suburban areas can be significant from an environmental point of view.

\section{Methodology AND Datasets}

The test area chosen for this project is situated on the southwest edge of Greater London and stretches from Wimbledon on the east side, to Hampton in the west, and from Richmond on the northern edge to Epsom in the south. Suburban land cover dominates the area. Being on the fringe of the London conurbation, the test area is one in which rapid urban expansion is taking place and in which difficult land use planning decisions will need to be taken in the future. Part of the test area is designated London "green belt." It also contains some historical parks such as that at Hampton Court Palace.

The image data used for this project were acquired on August 21, 2001 by the IKONOS-2 satellite (Space Imaging Corporation). They have been georeferenced using the Universal Transverse Mercator map projection and WGS84 ellipsoid. ${ }^{1}$ The complete dataset consists of panchromatic data with a spatial resolution of $1 \mathrm{~m}$ and multispectral data, collected in blue, green, red, and near-infrared bands, with 4-m resolution. Fig. 1 shows a color composite of the IKONOS multispectral image for the test area. The sketch map in Fig. 2 shows the locations of the readily identifiable geographical features. The image data of the test area consists of $3832 \times 3714$ pixels which covers an area of $15.33 \times 14.86 \mathrm{~km}$. The use of the very high resolution data from IKONOS is to facilitate a strong detection of the linear barriers such as roads. Although not critical to the computation of lacunarity and WMPS, it would be critical in any subsequent analysis in which connectivity of green areas is assessed.

Basic processing and analysis of the satellite imagery were carried out using the ENVI (V3.5) software package. The new algorithms required to compute landscape metrics from the satellite data were developed using IDL (V5.5), incorporating some functions from the ENVI function library.

Most natural landscapes are very complex, and it is difficult to quantify them using a single number. Landscapes are often characterized with metrics that each identify particular types of feature, such as variability of patch size or density of vegetation, which together describe the landscape. Many metrics are

${ }^{1}$ http://www.spaceimaging.com/products/ikonos/geo_techspec.htm

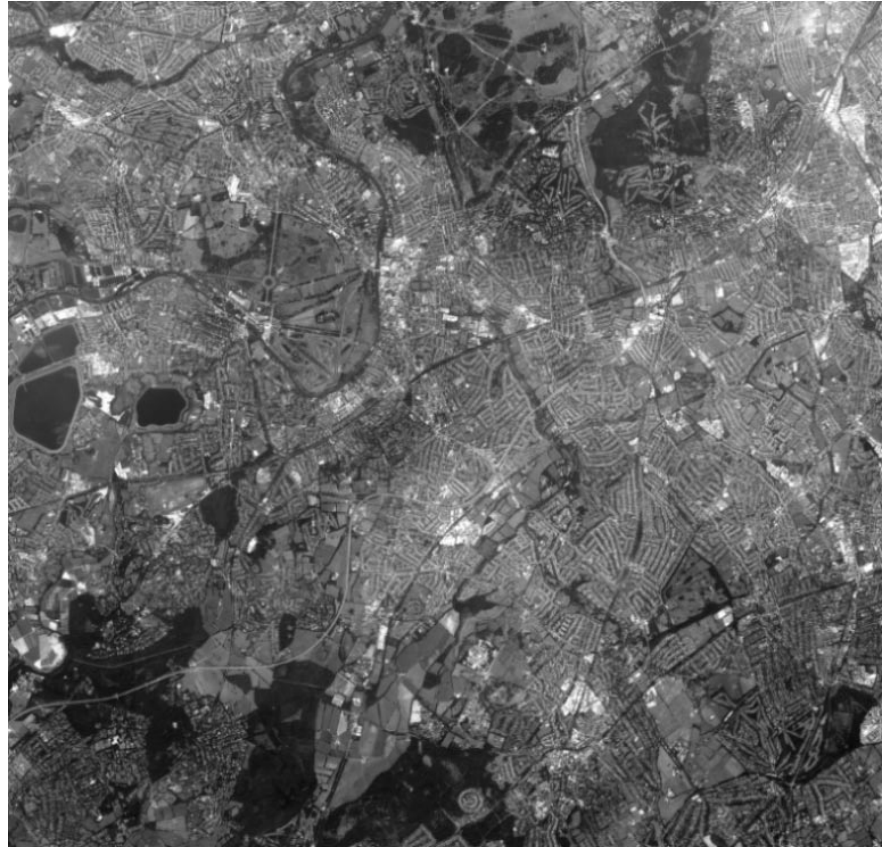

Fig. 1. IKONOS image of suburban test area, southwest London, U.K. Space Imaging LLC @ 9 2002. Supplied by NPA Group www.satmaps.com. Reprinted by permission.

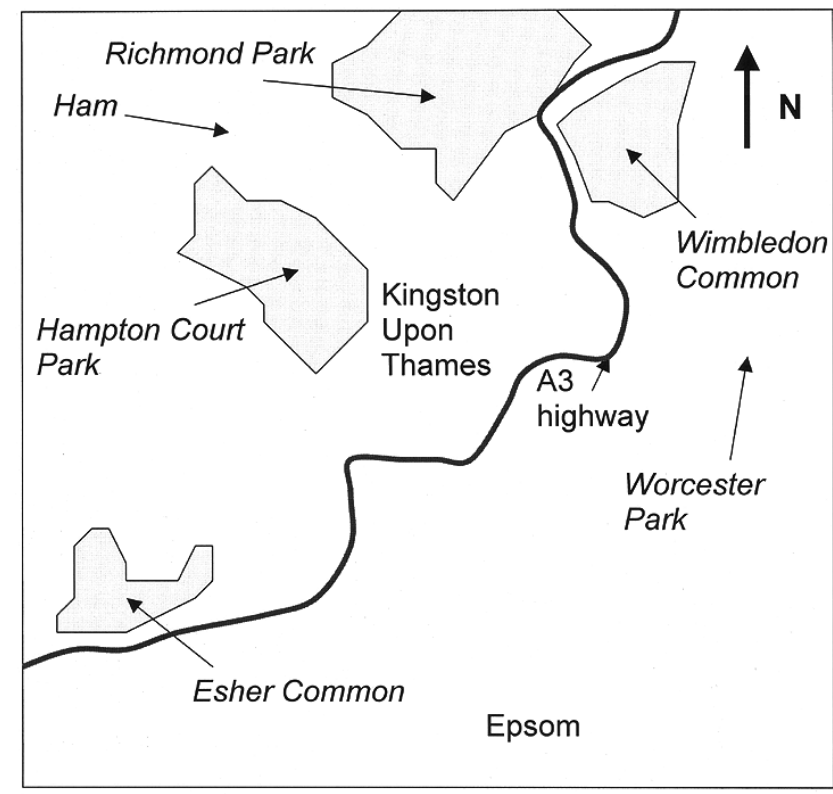

Fig. 2. Sketch map of image area showing location of principal geographical features.

available, and the ecologist or the land use planner must select the most appropriate ones from the toolbox to best measure the landscape structure of interest. In order to characterize suburban areas, image metrics have been used in this work that provide information about the relative distributions of the built-up spaces and of vegetated spaces in the test area.

In order to separate vegetated from built-up surfaces in the suburban environment, the normalized difference vegetation index (NDVI) can be used. NDVI has often been applied in land use studies and in mapping primary production, e.g., [26], 


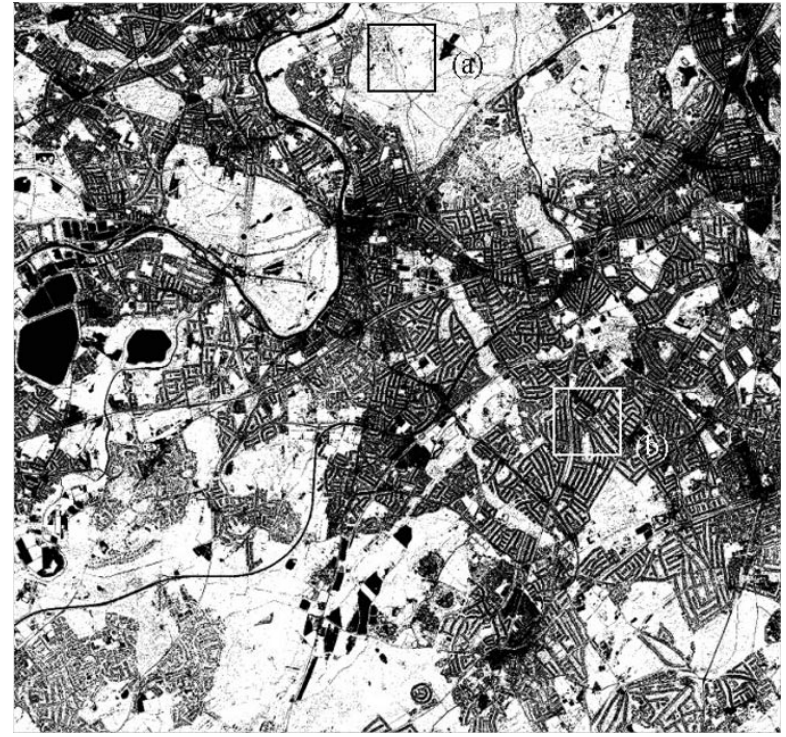

Fig. 3. NDVI image thresholded at a value of 0.3 .

though its use with IKONOS imagery has not been extensive. NDVI is given by

$$
\text { NDVI }=\frac{\text { NIR }- \text { VIS }}{\text { NIR }+ \text { VIS }}
$$

where NIR is the reflectivity in the near-infrared part of the spectrum and VIS is the reflectivity in the red part. IKONOS provides four bands of multispectral data as follows: Band 1: blue- 0.45-0.52 $\mu \mathrm{m}$; Band 2: green- 0.52-0.60 $\mu \mathrm{m}$; Band 3: red- 0.63-0.69 $\mu \mathrm{m}$; Band 4: near-infrared: 0.76-0.90 $\mu \mathrm{m}$. The red and near-infrared bands (bands 3 and 4) are used in the calculation of NDVI (as the VIS and NIR parameters, respectively). To extract useful information from the NDVI image it is thresholded. Pixels above the threshold are likely to be found at areas of significant vegetation. Several vegetation pixels group together to form vegetation patches. The size and distribution of the areas of these vegetation patches are important in characterizing the ecological nature of urbanized or semiurbanized areas. Fig. 3 shows a binary image with values -1 (in black) denoting nonvegetation land cover and +1 (in white) indicating vegetated land cover. This was derived from the test image in Fig. 1 by thresholding NDVI at a value of 0.3 , which was found by trying different thresholds until a good classification was found. Misclassifications result if the threshold is not chosen carefully.

(Using adaptive techniques to classify the NDVI image has also been attempted, to obtain a more local threshold for different parts of the image.) It can be seen that the vegetated areas are highly distinct in white, and nonvegetated such as buildings, roads, rivers, and water bodies (reservoirs) are shown in black. Striped areas corresponding to rows of residential houses separated by gardens are very clear at this resolution. The misclassification of pixels is estimated at $\sim 10 \%$. Overall, the NDVI image thresholded at 0.3 appears from local knowledge to give an accurate and usable separation of the vegetated and nonvegetated land cover in this area. This area also has excellent transportation networks into central London as well as amenities. It is, therefore, one of the areas in which the demand for new housing is most acute and where part of the government

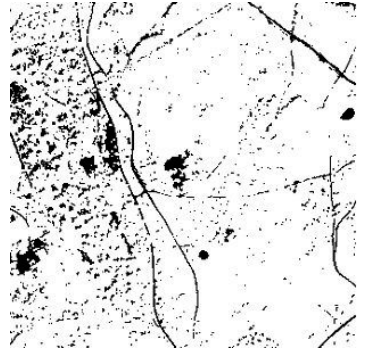

(a)

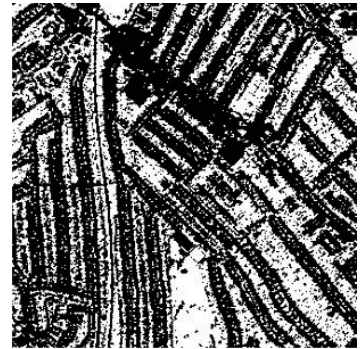

(b)
Fig. 4. NDVI images for two test regions. (a) Suburban parkland area (Richmond Park). (b) High-density residential area (Worcester Park).

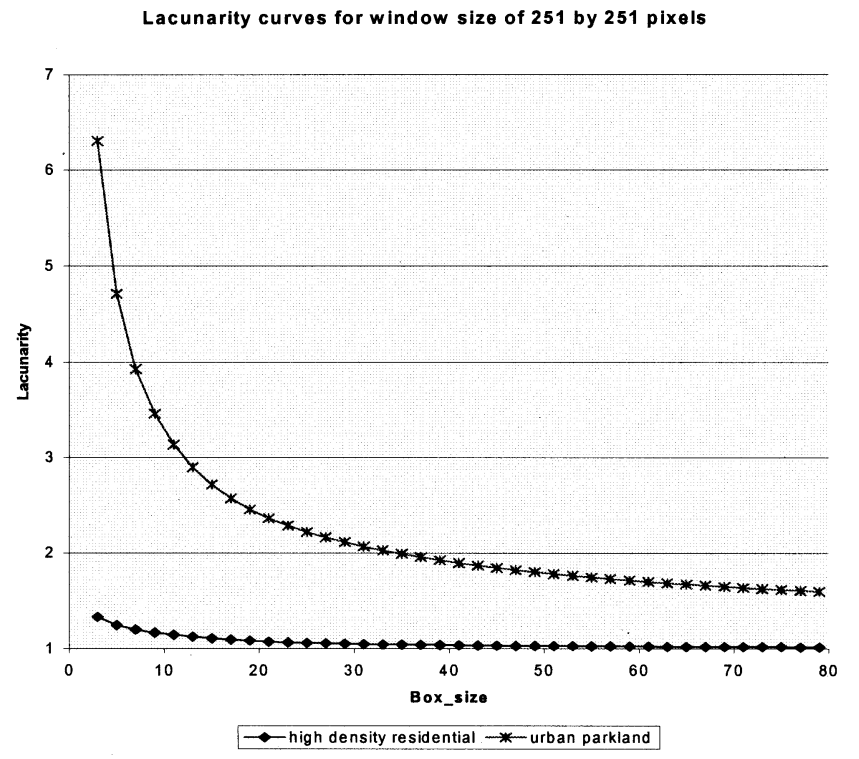

Fig. 5. Vegetation lacunarity curves for two test subareas from the image of Fig. 1, representing "suburban parkland" and "high-density residential" areas. A fixed window of size $251 \times 251$ pixels was used with varying box size.

strategy for housing development is being realized, thus leading to a rapid trend of urbanization.

\section{LANDSCAPE METRICS}

We have used two landscape metrics in this work to characterize the distribution of vegetation patches within suburban areas. The "weighted mean patch size" (WMPS) [27] and "lacunarity." WMPS provides information about the size distribution of vegetation patches in a region, and lacunarity provides an indicator of the spatial clustering of such patches.

The mean patch size and weighted mean patch size are measures for quantifying landscape structure. The mean patch size is the average size (area) of vegetative patches within a window. The weighted mean patch size is intended to better quantify landscape structure by including information on both patch size and number [27]. It is similar to the mean patch size, except that it is biased toward the size of large patches.

Lacunarity can be used as a measure of the distribution of patches of pixels in a scene [23]. The lacunarity value helps to compare two regions with identical patch sizes: the one with the highest "clumpiness" of patches rather than an even spatial scattering will have the highest lacunarity. Essentially, lacunarity is high when there is a range of patch sizes of a par- 


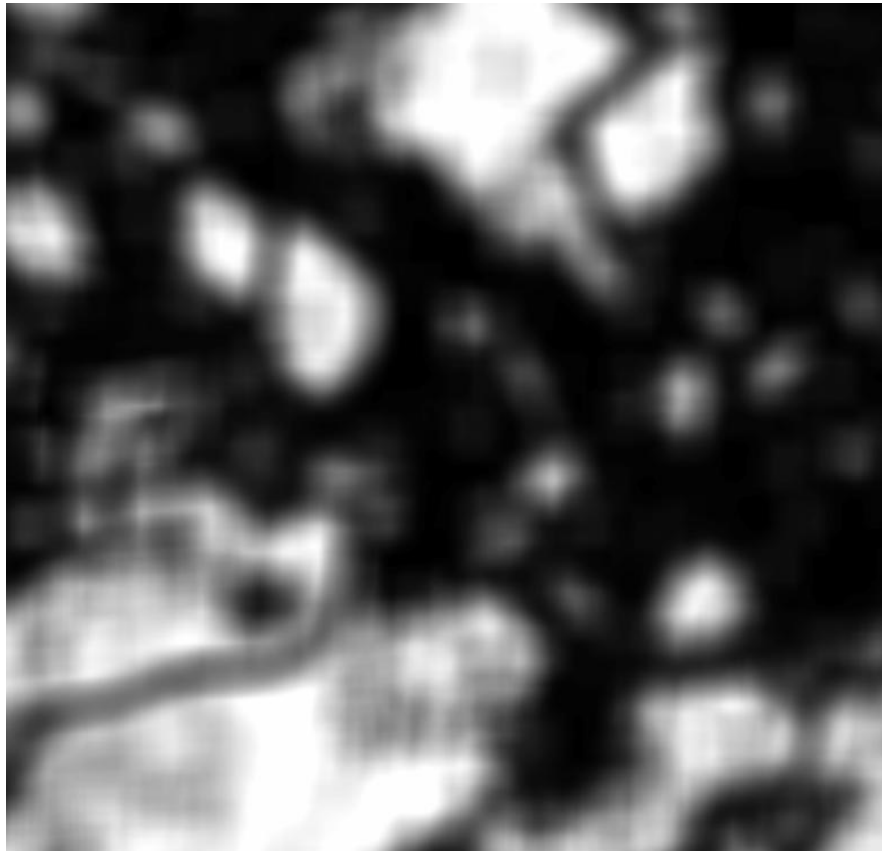

Fig. 6. WMPS image calculated from Fig. 1 with a moving window of size $251 \times 251$ pixels.

ticular type (vegetated, nonvegetated, etc.). To calculate lacunarity, a square box with a set width is moved across the image in a raster-scan fashion within a fixed image window, which is normally smaller than the full image size. In order to calculate vegetation lacunarity, at each position in the window a count is made of the number of interpatch pixels (nonvegetated pixels) within the square box in the thresholded NDVI image. These counts are summarized in a histogram. The mean and variance of the counts are calculated. The lacunarity $L$ is then given by

$$
L=\left(\frac{\text { variance }}{\text { mean }^{2}}\right)+1 \text {. }
$$

We have calculated the lacunarity (Fig. 5) in two different subareas of the image, shown in Fig. 4. The first area (suburban parkland) contains significant vegetation and was measured within Richmond Park. The second area is high-density residential and was measured near Worcester Park. The computation is performed using the interpatch pixels which are not of the type "vegetation" (i.e., coded -1 in the thresholded NDVI image).

\section{OBTAINING WMPS AND VEGETATION LACUNARITY IMAGES}

Within urban or suburban environments that are subject to necessary development (i.e., where housing development must take place because of population pressure), an appropriate urban land use planning strategy for "sustainability" will be to choose to develop the landscape in such a way as to ideally conserve, or at least reduce by the minimum amount, both WMPS and vegetation lacunarity in the region. Since both quantities only provide a characterization of a locality centred on a given pixel, regional planning decisions need to take into account the regional variations of these quantities.

An appropriate mechanism for achieving this is to compute WMPS and lacunarity "images" covering a geographical area,

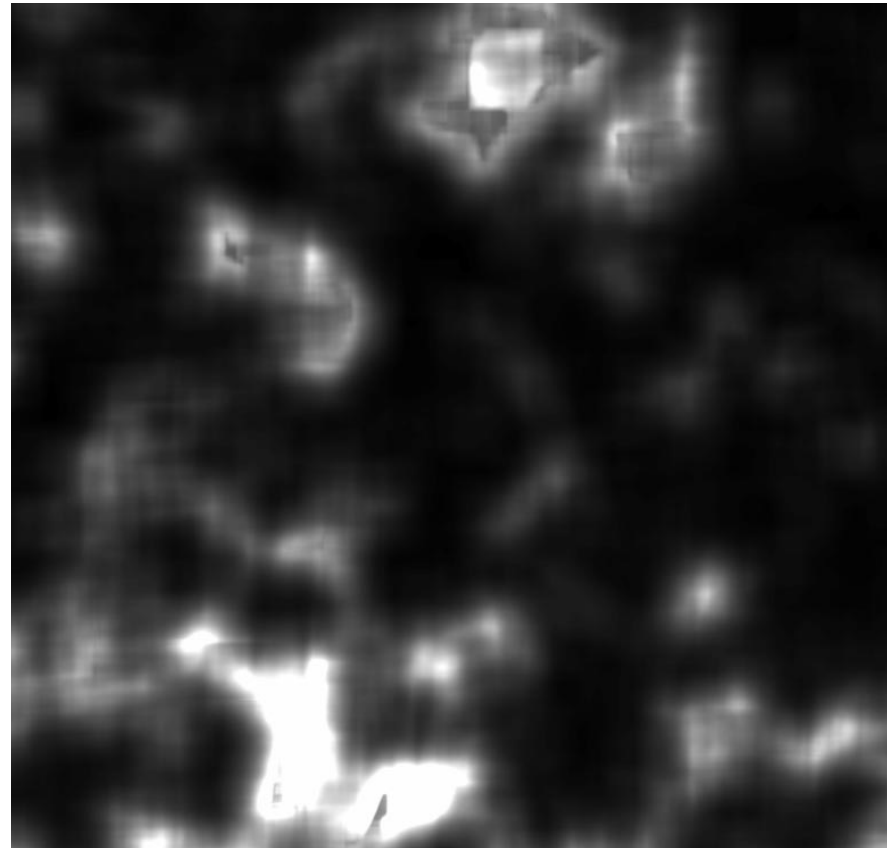

Fig. 7. Lacunarity image calculated from Fig. 1 with a moving window of size $251 \times 251$ pixels and a fixed box size of $7 \times 7$ pixels.

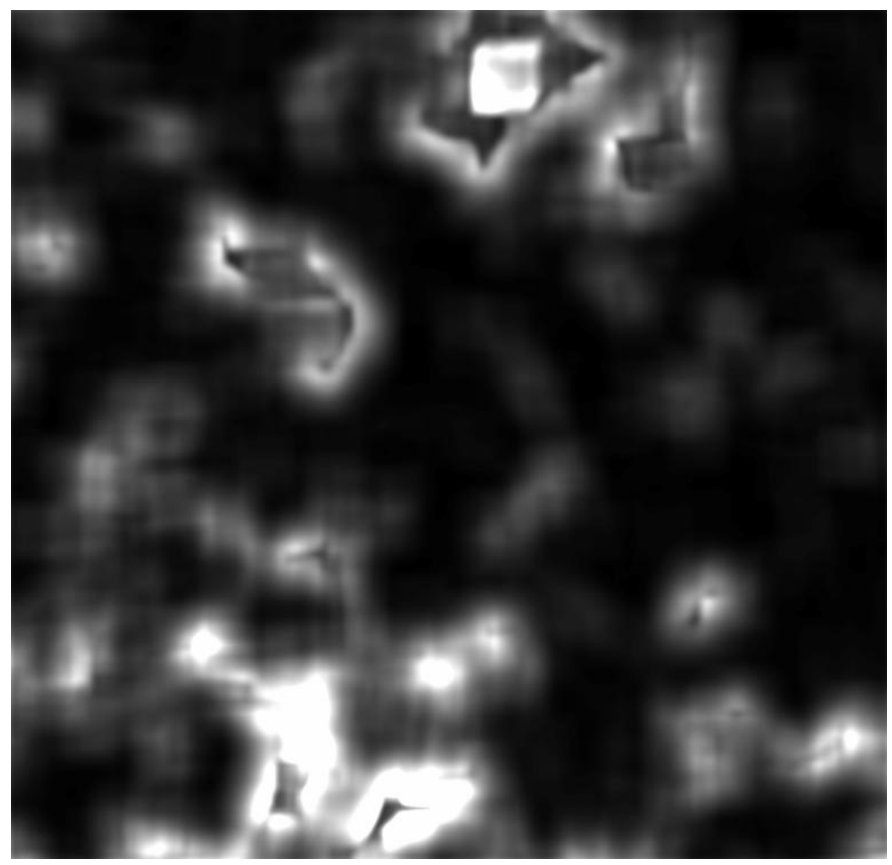

Fig. 8. Lacunarity image calculated from Fig. 1 with a moving window of size $251 \times 251$ pixels and a fixed box size of $51 \times 51$ pixels.

i.e., by moving the window within which these quantities are calculated over the entire input satellite image and calculating an array of WMPS and lacunarity values at the successive locations of the center of each window position. The measurement is assumed to be valid for the pixel location at the center of the window. The window has to be moved over every pixel in the image in order to generate an image illustrating the variability of the chosen metrics. The values of WMPS and lacunarity obtained can be mapped to grayscale values that can then be color 
TABLE I

Average Values of Weighted Mean Patch Size and Lacunarity of Different Types of Suburban Land Cover DeRIVED From the TeSt IMAGE OF SOUTH WeSt LONDON SUbuRBS

\begin{tabular}{|c|c|c|c|c|}
\hline & $\begin{array}{l}\text { Entire sub- } \\
\text { urban test } \\
\text { area }\end{array}$ & $\begin{array}{l}\text { Sub-urban } \\
\text { parkland } \\
\text { (Richmond } \\
\text { Park) }\end{array}$ & $\begin{array}{l}\text { Low density } \\
\text { residential } \\
\text { area } \\
\text { (Ham) }\end{array}$ & $\begin{array}{l}\text { High density } \\
\text { residential } \\
\text { (Worcester } \\
\text { Park) }\end{array}$ \\
\hline $\begin{array}{l}\text { Weight Mean } \\
\text { Patch Size } \\
\text { (pixels) }\end{array}$ & $100-62000$ & $\sim 50000$ & $\sim 10000$ & $\sim 500$ \\
\hline $\begin{array}{l}\text { Vegetation } \\
\text { Patch } \\
\text { Lacunarity } \\
\text { (box size } 7 \times 7 \\
\text { pixels) }\end{array}$ & $1.01-21$ & $\sim 4$ & $\sim 2$ & $\sim 1.2$ \\
\hline $\begin{array}{l}\text { Vegetation } \\
\text { Patch } \\
\text { Lacunarity } \\
\text { (box size } 51 x \\
51 \text { pixels) }\end{array}$ & $1.01-6$ & $\sim 1.8$ & $\sim 1.4$ & $\sim 1.05$ \\
\hline
\end{tabular}

coded using a smoothly changing color map for visualization purposes.

\section{EXAMPLE RESULTS OF REGIONAL WMPS AND VEGETATION LACUNARITY IMAGES}

Figs. 6-8 show color-coded WMPS and lacunarity images derived from the IKONOS-2 scene for the test area of Fig. 1.

Fig. 6 shows the weighted mean patch size for the image, calculated with a window size of $251 \times 251$ pixels. The spatial pattern of WMPS clearly indicates the main areas of vegetation, but also highlights localities in which some large vegetation patches exist among extensive built up areas. The dark areas have the lowest WMPS values and represent those parts of the landscape in which ecologically significant vegetation patches are not present. It is suggested that these could be targeted for urban development in the first instance. The WMPS ranged from 100 to 62000 pixels corresponding to areas of $0.0016-0.992 \mathrm{~km}^{2}$.

Fig. 7 is the lacunarity image, calculated with a window size of $251 \times 251$ pixels and a box size of $7 \times 7$ pixels. The lacunarity range was from 1.01 to 20.9. Whilst the spatial pattern of lacunarity is broadly similar to the WMPS image, there are some significant differences. In particular, road features have less effect, and high lacunarity values are confined to smaller areas where there is good vegetation patch "clumpiness." From an ecological perspective, the lacunarity image can be interpreted as indicative of the priority areas for preservation of existing natural vegetated land cover and of areas in which urban development should not take place. Fig. 8 is a lacunarity image calculated with a window size of $251 \times 251$ pixels and a box size of $51 \times 51$ pixels. This image is indicative of spatial clustering of vegetation patches at a larger scale. The lacunarity range was from 1.01 to 5.98 .

Table I gives a summary of the values of the WMPS and lacunarity in the test area as a whole and in the subimages of Fig. 4 representing different types of suburban land cover. The low-density residential areas and suburban parkland areas have lacunarity values (at box size of $7 \times 7$ pixels) in the range $2-4$, whereas the high-density residential area has a lacunarity value
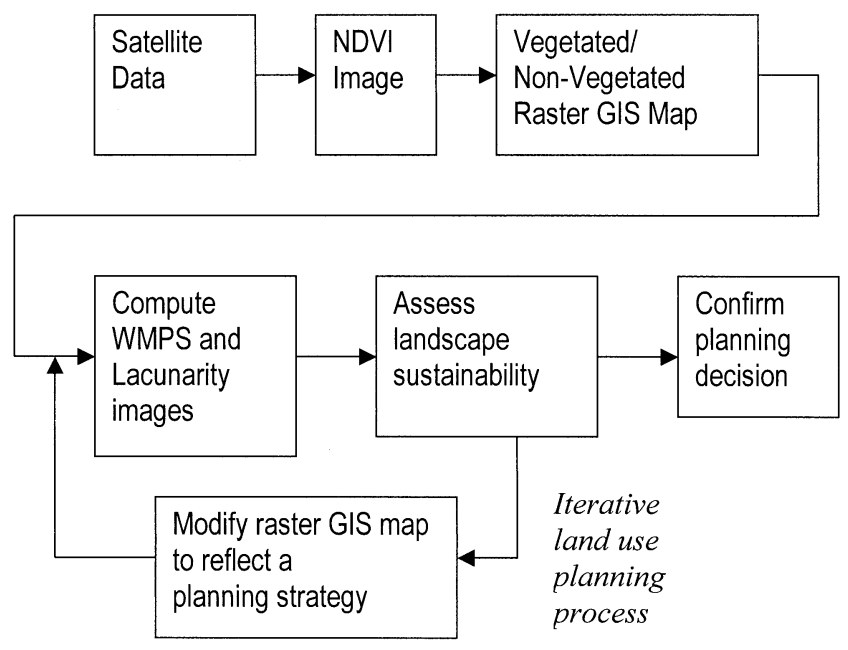

Fig. 9. Iterative land use planning scheme based on modeling process using WMPS and lacunarity images.

of the order of 1.2. At a box size of $51 \times 51$ pixels, the low-density residential areas and suburban parkland areas have lacunarity values in the range 1.4-1.8, whereas the high-density residential area has a lacunarity value of the order of 1.05 .

\section{DISCUSSION}

In this work, we have demonstrated how WMPS and lacunarity images, which provide a visual representation of the ecologically meaningful spatial structure of suburban areas, can be derived from very high resolution satellite imagery. By computing WMPS and lacunarity images, planners can visualize the current spatial distribution of WMPS and lacunarity in a geographical region. Whilst the visualization of such images by itself provides new insight into suburban landscapes, by making artificial changes to the greenness spatial distribution and recomputing WMPS and lacunarity, it would be possible to understand the local impacts of different land use planning strategies and modify those strategies accordingly (Fig. 9). WMPS and lacunarity images could, thus, become important tools in 
regional development planning in the suburban context. Whilst it is still too early to predict the full benefit of this approach, it is possible to see a significant role for WMPS, lacunarity, and other landscape ecological metrics, computed from very high resolution imagery as two-dimensional (2-D) image products, within suburban planning decision support systems. However, before this can become feasible, more work is needed to understand optimum strategies for employing such quantities. All landscape metrics require the selection of window sizes and, in some cases such as lacunarity, also a box size. By utilizing a variety of window and box sizes, a vast spectrum of 2-D image products can be derived. A key issue is to determine which ecological metric images from such a vast spectrum are the most meaningful and useful in the context of land use planning. The results from this work appear to show that for environmentally sustainable land use in suburban areas local WMPS should be maintained at values in excess of 10000 pixels (equivalent to $0.16 \mathrm{~km}^{2}$ ) and lacunarity at values exceeding 2.0 at box size $7 \times 7(28 \times 28 \mathrm{~m})$ and exceeding 1.4 at box size $51 \times 51$ pixels $(204 \times 204 \mathrm{~m})$. This corresponds to maintaining a relatively low density of housing and a good clustering of local green areas, which would be supportive of recreation and diversification of flora and fauna. However, more work is needed "calibrate" the land use planning and development process in terms of such metrics. From such an approach, it is possible to envisage the derivation of empirical development laws such as conservation of lacunarity, maximization of WMPS, or maintenance of minimum values of these and other quantities in particular urban or suburban contexts. High-resolution satellite imagery was motivated by the need to detect small-scale features. However, as the NDVI can only distinguish between vegetative and nonvegetative pixels, the classification is fairly unsophisticated.

The NDVI is a relatively simple way of assessing the spatial texture of ecological quality, as it only categorises into two classes. Consequently we are considering the recently proposed normalized difference built-up index (NDBI) [28].

\section{ACKNOWLEDGMENT}

The authors acknowledge and thank the Sustainable Technology Research Centre at Kingston University for the facilities necessary to carry out this project.

\section{REFERENCES}

[1] K. M. L. Rao, "Remote sensing for land-use planning," Int. J. Remote Sens., vol. 16, no. 1, pp. 53-60, Jan. 10, 1995.

[2] S. Chen, S. Zeng, and C. Xie, "Remote sensing and GIS for urban growth analysis in China," Photogramm. Eng. Remote Sens., vol. 66, no. 5, pp. 593-598, May 2000.

[3] P. Longley and V. Mesev, "The use of diverse RS-GIS sources to measure and model urban morphology," Geograph. Syst., vol. 4, no. 1, pp. 5-18, 1997.

[4] J. C.-W. Chan, K.-P. Chan, and A. G.-O. Yeh, "Detecting the nature of change in an urban environment: A comparison of machine learning algorithms," Photogramm. Eng. Remote Sens., vol. 67, no. 2, pp. 213-225, Feb. 2001.

[5] J. Gao and D. Skillcorn, "Capability of SPOT XS data in producing detailed land cover maps at the urban-rural periphery," Int. J. Remote Sens., vol. 19 , no. 15 , pp. 2877-2891, Oct. 1998.
[6] M. J. Barnsley and S. L. Barr, "Inferring urban land use from satellite sensor images using kernel-based spatial reclassification," Photogramm. Eng. Remote Sens., vol. 62, no. 8, pp. 949-958, 1996.

[7] C. C. Kontoes, V. Raptis, M. Lautner, and R. Oberstadler, "The potential of kernel classification techniques for land use mapping in urban areas using 5 m-spatial resolution IRS-1 C imagery," Int. J. Remote Sens., vol. 21, no. 16, pp. 3145-3151, Nov. 10, 2000.

[8] M. Pesaresi, "Texture analysis for urban pattern recognition using fineresolution panchromatic satellite imagery," Geograph. Environ. Model., vol. 4, no. 1, pp. 43-63, May 2000.

[9] J. Heikkonen, A. Varfis, I. Kanellopoulos, G. G. Wilkinson, K. Fullerton, and A. Steel, "A method for remote sensing based classification of urban areas," in Proc. 10th Scandinavian Conf. Image Analysis, vol. 2, Lapeenranta, Finland, June 9-11, 1997, pp. 1015-1022.

[10] J. Zhang and G. M. Foody, "A fuzzy classification of sub-urban land cover from remotely sensed imagery," Int. J. Remote Sens., vol. 19, no. 14, pp. 2721-2738, Sept. 20, 1998.

[11] _ _ "Fully-fuzzy supervised classification of sub-urban land cover from remotely sensed imagery: Statistical and artificial neural network approaches," Int. J. Remote Sens., vol. 22, no. 4, pp. 615-628, Mar. 10, 2001

[12] V. Mesev, "The use of census data in urban image classification," Photogramm. Eng. Remote Sens., vol. 64, no. 5, pp. 431-438, May 1998.

[13] J. Epstein, K. Payne, and E. Kramer, "Techniques for mapping suburban sprawl," Photogramm. Eng. Remote Sens., vol. 63, no. 9, pp. 913-918, Sept. 2002.

[14] Y. Dong, B. Forster, and C. Ticehurst, "Radar backscatter analysis for urban environments," Int. J. Remote Sens., vol. 18, no. 6, pp. 1351-1364, Apr. 1997.

[15] C. Small, "Estimation of urban vegetation abundance by spectral mixture analysis," Int. J. Remote Sens., vol. 22, no. 7, pp. 1305-1334, May 10, 2001

[16] B. R. P. Dawson and A. J. Parsons, "Texture measures for the identification and monitoring of urban derelict land," Int. J. Remote Sens., vol. 15, no. 6, pp. 1259-1271, Apr. 1994.

[17] Y. Zhang, "Detection of urban housing development by fusing multisensor satellite data and performing spatial features post-classification," Int. J. Remote Sens., vol. 22, no. 17, pp. 3339-3355, Nov. 20, 2001.

[18] D. A. Quattrochi, J. C. Luvall, D. L. Rickman, M. G. Estes Jr., C. A. Laymon, and B. F. Howell, "A decision support information system for urban landscape management using thermal infrared data," Photogramm. Eng. Remote Sens., vol. 66, no. 10, pp. 1195-1207, Oct. 2000.

[19] K. P. Gallo and J. D. Tarpley, "The comparison of vegetation index and surface temperature composites for urban heat-island analysis," Int. J. Remote Sens., vol. 17, no. 15, pp. 3071-3076, Oct. 1996.

[20] M. K. Ridd, "Exploring a V-I-S (vegetation-impervious surface-soil) model for urban ecosystem analysis through remote sensing: Comparative anatomy for cities," Int. J. Remote Sens., vol. 16, no. 12, pp. 2165-2185, 1995.

[21] S. Phinn, M. Stanford, P. Scarth, A. T. Murray, and P. T. Shyy, "Monitoring the composition of urban environments based on the vegetation-impervious-soil (VIS) model by subpixel analysis techniques," Int. J. Remote Sens., vol. 23, no. 10, pp. 4131-4153, Oct. 2002.

[22] H. Gulinck, H. Dufourmont, P. Coppin, and M. Kermy, "Landscape research, landscape policy and Earth obervation," Int. J. Remote Sens., vol. 21, no. 9, pp. 2541-2554, Sept. 2000.

[23] R. E. Plotnick, R. H. Gardner, and R. V. O'Neill, "Lacunarity indices as measures of landscape texture," Landscape Ecol., vol. 8, pp. 201-211, 1993.

[24] P. Peralta and P. Mather, "An analysis of deforestation patterns in the extractive reserves of Acre, Amazonia from satellite imagery: A landscape ecological approach," Int. J. Remote Sens., vol. 21, no. 13-14, pp. 2555-2570, Sept. 10, 2000.

[25] G. N. Bastin, J. A. Ludwig, R. W. Eager, V. H. Chewings, and A. C. Liedloff, "Indicators of landscape function: Comparing patchiness metrics using remotely-sensed data from rangelands," Ecolog. Indicators, vol. 1, no. 4, pp. 247-260, 2002.

[26] C. J. Tucker and P. J. Sellers, "Satellite remote sensing of primary production," Int. J. Remote Sens., vol. 7, pp. 1395-1416, 1986.

[27] B.-L. Li and S. Archer, "Weighted mean patch size: A robust index for quantifying landscape structure," Ecological Modeling, vol. 102, pp. 353-361, 1997.

[28] Y. Zha, J. Gao, and S. Ni, "Use of normalized difference built-up index in automatically mapping urban areas from TM imagery," Int. J. Remote Sens., vol. 24, pp. 583-594, 2003. 


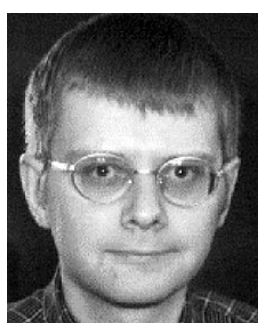

Darrel R. Greenhill received the B.S. degree in physics with microcomputer electronics and the Ph.D. degree in machine vision, both from Royal Holloway, University of London, London, U.K., in 1990 and 1994, respectively.

$\mathrm{He}$ is currently a Senior Lecturer within the School of Computing and Information Systems, Kingston University, Surrey, U.K., and is a member of the Digital Imaging Research Centre. He has authored or coauthored over 30 technical papers related to digital imaging.

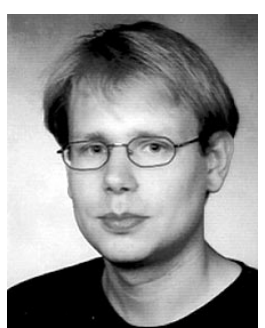

Lennart T. Ripke is currently pursuing a degree in optical technology and image processing at the University of Applied Sciences, Darmstadt, Germany.

He recently completed a six-month project in the Sustainable Technology Research Centre, Kingston University, Surrey, U.K., on sustainable land use planning using remote sensing and geographical information systems.

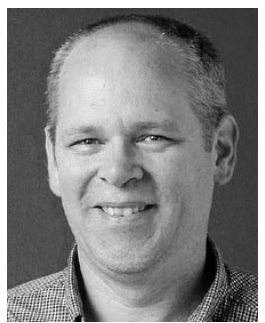

Adrian P. Hitchman received the B.S. degree with honors from the University of New England, Armidale, Australia, in 1982, and the Ph.D. degree from the Australian National University, Canberra, Australia, in 2000 , both in geophysics

He initially was with Geoscience Australia, Canberra, Australia, where he was responsible for mapping the geomagnetic field in the southwest Pacific, before becoming a science/mathematics teacher. More recently, he has been a Visiting Researcher in the Sustainable Technology Research Centre, Kingston University, Surrey, U.K., where he has been involved in research in the characterization of urban environments using high-resolution remotely sensed multispectral imagery.

Dr. Hitchman is a member of the Australian Society of Exploration Geophysicists, the European Geosciences Union, and the American Geophysical Union.

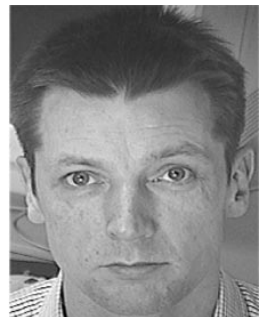

Graeme A. Jones received the Ph.D. degree in computer vision from Kings College, London, U.K.

$\mathrm{He}$ is currently Director of the Digital Imaging Research Centre, Kingston University, Surrey, U.K. He has over 15 years experience in image and video sequence analysis, intelligent systems, and multimedia data communications and has managed a number of industrial and government-funded projects in these areas. Recently, he been responsible for video/image analysis projects supported by the film and specialeffects industry (Computer Film Company Ltd. U.K. and Dynamic Digital Depth Pty. Ltd., Australia) and by the video security industry (Primary Image Vision Systems Ltd.). He is currently Co-Investigator on the EU INMOVE (IST-2001-37422) project developing an expandable set of software tools enabling the provision of a new range of intelligent video-based services to end users in various mobile/wireless networks. He has authored or coauthored over 80 technical papers related to digital imaging and video data communications.

Dr. Jones chaired the British Machine Vision Workshop on Visual Surveillance in 2000 and was Co-Chair of the IAPR Workshop on Advanced VideoBased Surveillance Systems in 2001.

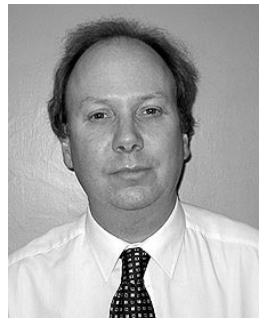

Graeme Wilkinson (M'00) received the B.S. degree in physics from Imperial College London, London, U.K., and the D.Phil. degree in atmospheric physics from the University of Oxford, Oxford, U.K., in 1976 and 1980 , respectively.

He is currently a Professor of Computer Science and Dean of the Faculty of Applied Computing Sciences, University of Lincoln, Lincoln, U.K. From 1997 to 2002, he was formerly Head of the School of Computing and Information Systems, Kingston University, London, U.K. From 1988 to 1997, he was a Staff Scientist at the Space Applications Institute of the European Commission, Joint Research Centre, Ispra, Italy. From 1998 to 2000, he was a Coordinator of the European Commission-funded international concerted action "MAVIRIC" on machine vision approaches in remotely sensed image understanding. His research interests include neural network classification, data fusion, and machine vision techniques applied to very high resolution remote sensing. 